\title{
Молдавская Военная академия: трансформирование образования офицеров
}

\author{
Джон Ф. Трокселл ${ }^{*}$
}

\section{Профессиональное военное образование в контексте}

Двадцать первый век возвестил эпоху динамических изменений в международной среде безопасности, которые требуют новых способностей и новых ответов на новые угрозы, эпоху возросшей вероятности многонациональных операций, сопровождаемые экономическими затруднениями, которые вынуждают государства урезать военные бюджеты. Когда речь идет о потребностях военных элементов в рамках всего национального устройства и национальных ресурсов, то все они подчиняются одному и тому же императиву в отношении развития лидеров и профессионального военного образования. Генерал Мартин Демпси, председатель Объединенного комитета начальников штабов США, сформулировал этот императив в недавно опубликованных «Стратегических указаниях объединенным вооруженным силам». Он обозначил необходимость «усилить развитие лидеров на всех уровнях Совместного Профессионального Военного Образования», с тем чтобы создавать принципиальных лидеров, «которые смогут сочетать новые способности новыми способами в комплексной среде». ${ }^{1}$ Всем странам необходимо реформировать и усовершенствовать свои программы профессионального военного образования.

С точки зрения Соединенных Штатов и НАТО, второй императив относится к усилиям, предпринятым для оказания помощи другим странам в усовершенствовании программ профессионального военного образования. Ключевым принципом недавно опубликованных указаний для обороны США Укрепление глобального лидерства США: приоритеть обороны в двадиать первом веке является развитие потенциала партнерства. ${ }^{2}$ Предыдущие стратегические документы так же подчеркивали важность деятельности, направленной на усиление профессионализма вооруженных сил партнеров, и бывший министр обороны США, Роберт Гейтс, в статье, озаглавленной «Помогая другим защищать себя», опубликованной в журнале Foreign Affairs, развил далее эту концепцию, подчеркнув значение строительства

* Джон Трокселл является академическим соруководителем инициативы ПСОСО-Молдова, и профессором-исследователем в Институте стратегических исследований Военного стратегического колледжа сухопутных войск в Карлайле, штат Пенсильвания.

1 Gen. Martin Dempsey, "Chairman's Corner: Strategic Direction to the Joint Force," 6 February 2012; доступно на: www.defense.gov/News/NewsArticle.aspx?ID=67077.

2 Sustaining U.S. Global Leadership: Priorities for $21^{\text {st }}$ Century Defense (Washington, D.C.: U.S. Department of Defense, 5 February 2012); доступно на: http://www.defense.gov/news/ defense_strategic_guidance.pdf. 
институционального потенциала и человеческого капитала стран-партнеров. ${ }^{3}$ «Декларация саммита по оборонным способностям» саммита НАТО в Чикаго в 2012 году так же высветила значение связей со странами-партнерами и необходимость расширять образование и квалификацию. ${ }^{4}$ Укрепление потенциала партнеров в определенной степени должно быть сосредоточено на оказании помощи партнерам и их программам профессионального военного образования (ПВО). Только через укрепление потенциала партнеров, их способности действовать в мультинацинальном окружении, можно ответить на вызовы глобальной безопасности и максимизировать глобальную стабильность.

\section{Молдавский опыт}

Программа Совершенствования Образования в Сфере Обороны в Молдовы была инициирована на основании обращения президента Воронина к Генеральному секретарю НАТО в апреле 2008 года, в котором излагалась просьба об оказании помощи для «постепенного приведения программ [Военного института] в соответствие с западными стандартами» в качестве одной из ключевых целей Индивидуального Плана Действий по Партнерству (ИПДП). Когда Молдова получила независимость от Советского Союза в 1991 году, в республике не осталось никакого военного института или военной образовательной инфраструктуры. Фундамент профессионального военного образования (ПВО) в Республике Молдова основывался на советской модели, и национальное руководство понимало, что необходим переход к новой эпохе. В 1992 году был создан Военный институт и началось ведение двухгодичного курса для обучения будущих офицеров. В 1996 году программа была расширена до трех лет, а затем в 2002 году до нынешней четырехлетней программы. Первый «четырехлетний выпуск» закончил обучение в 2006 году. Четырехлетний учебный план соответствует по закону об образовании Молдовы и Болонским соглашениям от 1999 года требованиям к институту, осуществляющий первый уровень высшего образования и дающий образовательную степень бакалавра.

В ответ на просьбу президента Воронина НАТО организовало многонациональную команду из профессиональных военных и специалистов по образованию для осуществления оценочного визита в январе 2009 года с тем, чтобы оценить образовательный и квалификационный потенциал Военного института молдавских вооруженных сил. Оценивание включало анализ существующих программ для основного курса обучения, совместного курса повышенного уровня, курса для младших штабных офицеров и обмен мнениями о будущей программе штабного

3 Robert M. Gates, "Helping Others Defend Themselves," Foreign Affairs (May/June 2010); доступно на: www.foreignaffairs.com/articles/66224/robert-m-gates/helping-others-defendthemselves.

4 NATO Press Release, "Summit Declaration on Defense Capabilities: Toward NATO Forces 2020,” 20 Мау 2012; доступно на: http://www.nato.int/cps/en/natolive/official_texts_ 87594.htm?mode=pressrelease. 
курса для старших офицеров. Основные рекомендации включали предложения о коррекциях в существующем четырехлетнем основном курсе для получения степени бакалавра (первый уровень обучения), относящиеся к задаче создать «граждан-солдатов». Эти коррекции предполагали включение в программу дополнительных курсов лидерства, гражданско-военных отношений и связанных с ними вопросов. Эта работа должна была быть направлена на модернизацию учебных планов и включение в них западных НАТО-вских элементов. Конечной целью учебной программы было создание лидеров, открытых к обществу, которое они защищают, чувствующих себя комфортно в работе со средствами массовой информации и знающих хотя бы один иностранный язык. Военному институту так же было рекомендовано разработать программу для обучения по методике преподавания для специалистов по образованию, преподавателей и инструкторов.

Наиболее амбициозной была рекомендация создать курс для старших офицеров, в том числе программу для получения образовательной степени магистра (второй уровень высшего образования). Ко времени проведения оценочного визита в Молдовы не было никакого дополнительного военного образования, кроме курса для младших штабных офицеров. Сотрудники Военного института выразили мнение (нашедшее поддержку на самом высоком уровне в молдавском министерстве обороны), что кадровым офицерам необходимы дополнительные возможности как для высших военных исследований, так и возможность получить гражданскую образовательную степень магистра. Поэтому, в соответствие с молдавским законом об образовании и Болонскими соглашениями, они предложили (и оценивающая команда согласилась с ними) рассмотреть возможность создания программы для второй степени высшего образования в области военных искусств и военных наук или исследований в сфере обороны. Эта программа потребует приблизительно восемнадцать месяцев, и она будет открыта для старших офицеров (подполковников) и старших гражданских сотрудников ведомств, связанных с национальной безопасностью (таких как министерство обороны и министерство иностранных дел).

Последняя рекомендация касалась создания Центра для стратегических исследований и исследований в сфере безопасности. Этот центр в основном занимался бы разрабатыванием концепций и доктрин для молдавских вооруженных сил и осуществлял бы синергетическое использование профессорско-преподавательского состава и ресурсов расширенного Военного института.

Через несколько месяцев, в мае 2009 года, другая многонациональная группа вернулась в Республику Молдову, и в сотрудничестве с администрацией и преподавательским составом Военного института разработала как перспективный план, так и подробный план действий на следующий год. Ниже приведено описание долгосрочного плана.

В соответствие с долгосрочным планом, осуществление ПСОСО включало подробную разработку ежегодных планов действий (примерный план действий представлен ниже в Таблице 1), которые на первое время были сфокусированы на разработку программ и развитие преподавательского состава. 


\section{План действий для развития военного образования по ПСОСО-Молдова \\ Военная академия Республики Молдова}

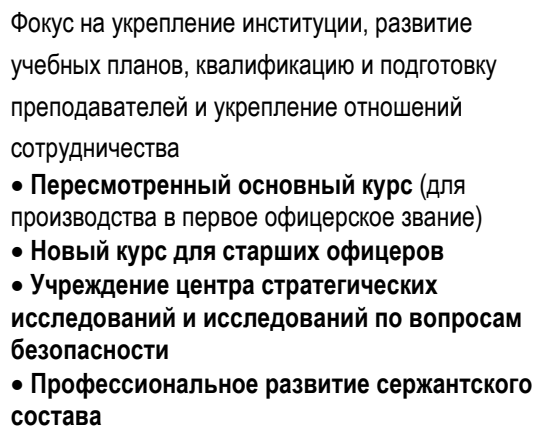

- Пересмотренный основный курс (для производства в первое офицерское звание)

- Новый курс для старших офицеров

- Учреждение центра стратегических исследований и исследований по вопросам безопасности

- Профессиональное развитие сержантского состава

- Академический обзор и оценка группы НАТО, май'10 (дорожная карта и план действий)

- Семинар по разработке учебного плана, январь'11

- Лекционные визиты и визиты для разработки программ, сентября'10 по апрель'11

- Поддержка исследовательскому центру, март'11

- Визиты для ознакомления, февраль'11 \& март'11

- Оценка, январь'09

- Разработка плана. май'09

- Акад. обзор группы НАТО, ноябрь'09

- Одобрение двухсторонних

консультаций по обороне, январь'10
Год 3 (2011-2012+)

Продолжение

последующих

мероприятий и

координация.

Движение вперед к

самостоятельности.

План устойчивого

развития.

$\int$

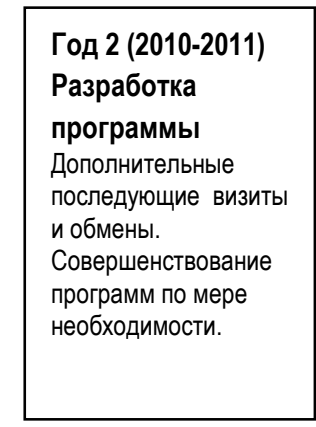

Год 1 (2009-2010)

Разработка

программы

Начальные визиты для

планирования и обмены,

ссрокусированные на

конкретных вопросах
Начаты новые курсы

- 1-й год основн. курса

- Курс для ст. офицеров

- Сержантские курсы

- Ежегодный анализ

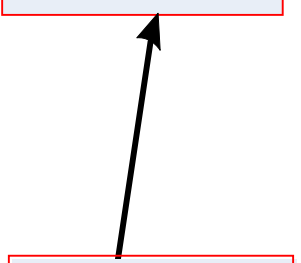

Разработаны

новые курсы

- Утверждение МО

и $\mathrm{MOH}$

- Создание

исследова-

тельского центра.

Фигура 1: Долгосрочный план ПСОСО для реформирования военного образования в Молдове.

В дополнение к семинарам, связанным с этими тремя темами, более целенаправленные мероприятия были проведены как для обучения преподавателей, так и для оказания им помощи в создании конкретных курсов, которые были включены в расширенные академические программы. В их число входили лидерство, глобализация, военно-гражданские отношения, медиа и коммуникации, элементы военной науки и некоторые другие. Дополнительно к мероприятиям, координируемым 
и проводимым членами рабочей группы ПСОСО, осуществлялась и другая сопутствующая деятельность, которая включала семинары по дистанционному обучению, семинары по методологии преподавания, курсы школы НАТО для повышения квалификации преподавателей и программы, предлагаемые Бюро Международной Языковой Координации. Были организованы несколько ознакомительных визитов для преподавателей в подобные военные образовательные институции в Румынии, такие как Румынский Национальный Университет Обороны, и в Соединенные Штаты, в том числе в Центр передового опыта в Форт Бенинге, штат Джорджия, и Командно-штабной колледж в Форт Ливенуорте, штат Канзас.

В конце каждого года проводился детальный анализ выполненных мероприятий (AВМ), часто одновременно с проводимым НАТО процессом анализа выполнения ИПДП. В каждом случае АВМ содействовали ключевые члены многонациональной рабочей группы и преподаватели из Военного института. План действий на следующий год оттачивался путем учета предыдущего опыта в отношении определения расписания визитов с целью максимизировать время работы с преподавателями и слушателями, учета растущих потребностей преподавательского со-

Таблица 1: Примерный план действий (План действий Молдавского военного института на 2010-2011 год, к июлю 2010 года).

\begin{tabular}{|c|c|c|c|c|c|c|}
\hline$\#$ & Число & Мероприятие & Участники & Проект & $\begin{array}{l}\text { Финан- } \\
\text { сирует }\end{array}$ & Статус \\
\hline 1 & $\begin{array}{l}28 \\
\text { июня-1 } \\
\text { июля } \\
2010\end{array}$ & $\begin{array}{l}\text { Лекция \& сессия I по } \\
\text { разработке про- } \\
\text { граммы: Междуна- } \\
\text { родная безопасность }\end{array}$ & $\begin{array}{l}\text { Академия Обо- } \\
\text { роны Нидерлан- } \\
\text { дов (группа из } \\
\text { трех человек) }\end{array}$ & $\begin{array}{l}\text { Преподаватели } \\
\text { основного и } \\
\text { старшего курса, } \\
\text { группа по разра- } \\
\text { ботке программ }\end{array}$ & $\begin{array}{l}\text { Нидер- } \\
\text { ланды }\end{array}$ & $\begin{array}{l}\text { Выпол- } \\
\text { нено }\end{array}$ \\
\hline 2 & $\begin{array}{l}5-7 \\
\text { сен- } \\
\text { тября } \\
2010\end{array}$ & $\begin{array}{l}\text { Лекция \& сессия II по } \\
\text { разработке про- } \\
\text { граммы: Лидерство и } \\
\text { этика }\end{array}$ & $\begin{array}{l}\text { ВСК США (Док- } \\
\text { тор Крейг Бул- } \\
\text { лис, подп. Винс } \\
\text { Линденмайер) }\end{array}$ & $\begin{array}{l}\text { Преподаватели } \\
\text { основного и } \\
\text { старшего курса, } \\
\text { группа по разра- } \\
\text { ботке программ }\end{array}$ & $\begin{array}{l}\text { ПСОСО } \\
\text { (ФВИ) }\end{array}$ & $\begin{array}{l}\text { Сплани- } \\
\text { ровано }\end{array}$ \\
\hline 3 & $\begin{array}{l}11-16 \\
\text { октяб- } \\
\text { ря } \\
2010\end{array}$ & $\begin{array}{l}\text { Лекция \& сессия III по } \\
\text { разработке про- } \\
\text { граммы: Менеджмент } \\
\text { обороны \& Экономика }\end{array}$ & $\begin{array}{l}\text { Канадская ака- } \\
\text { демия обороны } \\
\text { (Доктор Крейг } \\
\text { Стоун) }\end{array}$ & $\begin{array}{l}\text { Преподаватели } \\
\text { основного и } \\
\text { старшего курса, } \\
\text { группа по разра- } \\
\text { ботке программ }\end{array}$ & Канада & $\begin{array}{l}\text { Выпол- } \\
\text { няется }\end{array}$ \\
\hline 4 & $\begin{array}{l}\text { Ок- } \\
\text { тябрь } \\
2010 \\
\text { (уточ- } \\
\text { няется) }\end{array}$ & $\begin{array}{l}\text { Введение в стандар- } \\
\text { тизацию в НАТО } \\
\text { (анализ программы по } \\
\text { стандартизации в } \\
\text { НАТО) }\end{array}$ & $\begin{array}{l}\text { Стандартизаци- } \\
\text { онное агентство } \\
\text { НАТО (подпол- } \\
\text { ковник Петри) }\end{array}$ & Основной курс & HATO & $\begin{array}{l}\text { Выпол- } \\
\text { няется }\end{array}$ \\
\hline 5 & $\begin{array}{l}\text { Ноябрь } \\
2010 \\
\text { (уточ- } \\
\text { няется) }\end{array}$ & $\begin{array}{l}\text { Технология практиче- } \\
\text { ской подготовки по } \\
\text { тактике и обзор про- } \\
\text { граммы }\end{array}$ & $\begin{array}{l}\text { Канадская ака- } \\
\text { демия обороны }\end{array}$ & Основной курс & Канада & $\begin{array}{l}\text { Выпол- } \\
\text { няется }\end{array}$ \\
\hline
\end{tabular}


става и слушателей по мере развития программ обучения, и с использованием возможностей, которые предоставляют различные спонсирующие институции и государства.

Чтобы осуществить значительную трансформацию и развитие молдавской программы ПВО, в 2010 году Военный институт был преобразован в Молдавскую военную академию (МВА) им. «Александру сел Бун». Министерство обороны и министерство образования официально утвердили учебные планы трансформированного основного курса и нового курса для старших офицеров весной 2011 года. В сентябре того же года, МВА успешно начала выполнение учебного плана для курсантов первого курса, которые закончат четырехлетнее обучение в 2015 году, получив степень бакалавра. В том же месяце начался и новый курс для старших офицеров с двадцатью слушателями, построенный на принципах западного ПВО. Студенты завершат обучение в декабре 2012 года, получив степень магистра. Кроме измененных и новых учебных планов, отличительной чертой усовершенствованной программы обучения в МВА является акцент на усовершенствование преподавателей, реализацию серьезных изменений в технике преподавания и менеджмента занятий. Оба курса получили положительные внутренние оценки и от слушателей, и от преподавателей. При последнем ежегодном анализе и оценке, трансформированный основной курс и новый курс для старших офицеров были оценены как отвечающие всем поставленным целям, таким образом являясь примером для подражания в рамках инициативы ПСОСО, который потенциально можно предлагать и другим странам.

\section{Ключи к успеху}

Трансформация программы ПВО Республики Молдова была осуществлена в относительно короткий период, и осуществлена страной у которой определенно нет излишка ресурсов. Успешное развитие и применение программы Молдавской военной академии совершенствования ПВО зависели от нескольких ключевых факторов. В их число входили поддержка на национальном уровне; активное участие администрации и преподавателей МВА; многонационального характера команды НАТО и систематичного содействия ключевых членов этой команды; и инкорпорирование нескольких важных дополнительных международных программ ПВО.

Как было упомянуто в начале этой статьи, желание и решимость трансформировать военное образование в молдавских вооруженных силах появились в верхах государственного управления, и несмотря на смены политического руководства страны, эта поддержка всегда была. После начального оценочного визита, рекомендации рабочей группы были рассмотрены господином Виталием Врабие, министром обороны и генерал-майором Ионом Коропсеан, начальником генерального штаба. Господин Врабие выразил желание провести ускоренные реформы и модернизацию Военного института, полностью поддержал принятие стандартов НАТО и дал понять, что эти шаги являются основными приоритетами. В течение всего процесса, большим подспорьем было то, что президент, министр обороны и секретарь совета безопасности всегда поддерживали программу трансформирова- 
ния Военного института и стремление обеспечить сравнимое военное образование офицерам и гражданским сотрудникам в сфере обороны. Перед самым началом новых курсов в Академии, бригадный генерал Юрий Доминик, тогда начальник обороны Молдовы, прокомментировал общую цель и потенциал Программы Совершенствования Образования в Сфере Обороны в Молдовы, констатируя, что эта программа «это не просто новые учебные планы, но и новое мышление». Полковник Михаил Буклис, начальник МВА, был идеальным медиатором между администрацией и преподавателями МВА и национальным руководством. Единство целей и действий ясно было продемонстрировано в полноценной реализации этой программы.

Вторым ключевым фактором являлось активное участие преподавателей и администрации Молдавской военной академии. Эта программа никогда не была «утвержденным решением», основанным на существующих учебных планах ПВО, которое группа западных профессиональных военных и специалистов по образованию навязывала согласной группе молдавских офицеров. Совсем наоборот, как было отмечено выше с полным уважением к национальному руководству, руководство и преподаватели МВА полностью контролировали и принимали активное участие в процесс трансформации. Понимание необходимости перемен проистекало из понимания сложности среды безопасности в двадцать первом веке и потребности в квалифицированных специалистов в сфере государственной безопасности и обороны. Члены академического состава MBA активно участвовали в многочисленных программах Консорциума «Партнерства ради мира» (ПРМ).

По мере того как инициатива ПСОСО начала расширять и совершенствовать свою деятельность, становилось все более очевидна необходимость общей примерной программы ПВО для офицеров. Разработка этого документа основывалась на желании, чтобы он отвечал потребностям стран-партнеров, которые действительно использовали бы части такой программы и поэтому к созданию примерной программы были привлечены преподаватели из институций ПВО стран-партнеров. Один из основных игроков в этой работе был подполковник Серджиу Сарамет, начальник факультета объединенных родов войск молдавской военной академии. Он помогал рабочей группе, проводившей предварительную валидизацию, которой руководил подполковник Линдмейер из Военного колледжа сухопутных войск США. Работа по трансформации основного курса МВА послужила пробным тестом работоспособности примерной программы. Преподавательский состав MBA принимал участие в разработке примерной программы ПВО для Консорциума ПРМ, а использование примерной программы облегчило успешную реализацию программы MBA: ситуация в которой все в выигрыше. В MBA так же состоялись несколько международных мероприятий ПРМ, в том числе семинары по дистанционному обучению и методике преподавания. Активное участие членов академического состава и администрации МВА существенно помогло успеху их программ и дальнейшему развитию деятельности ПСОСО.

Многонациональный характер рабочей группы ПСОСО-Молдова с самого начала стал третьим основным фактором. В первичном оценивании принимали уча- 
стие представители шести стран НАТО и стран-партнеров, и далее были сформированы две основные рабочие группы, обеспечивающие общее содействие их коллегам в Молдове. Представители Академии обороны Нидерландов, Чешского университета обороны и Военной академии Швейцарии сотрудничали с преподавателями МВА под руководством подполковника Сарамета в создании нового учебного плана для основного курса. Работе по программе курса для старших офицеров помогали преподаватели из Командно-штабного колледжа сухопутных войск США и Национального университета обороны Румынии, а взаимодействие осуществлялось подполковником Серджиу Плоп, начальником командно-штабного колледжа МВА. Все эти институции предоставили МВА для рассмотрения свои идеи и свои примерные программы. Доминирующая роль европейских институций ПВО была особенно важной для проработки вопросов, связанных с Болонским аккредитационным процессом.

Ввиду относительно короткого периода для осуществления трансформации, было важно обеспечить непрерывное взаимодействие с рабочими группами НАТО, чтобы была оказана вся необходимая помощь. Основные члены рабочих групп были постоянно заняты в течение всего двухгодичного процесса разработки. Повторяющиеся ангажементы одних и тех же членов рабочих групп и их коллег укрепляли доверие, углубляли диалог и способствовали готовности принимающей институции принять перемены и трансформации. В дополнение к двум основным рабочим группам, упомянутых выше, несколько других стран, в том числе Канада и Латвия, предоставили экспертов по конкретным дисциплинам для ведения семинаров по разработке учебных программ. Другим аспектом многонационального характера этой работы было развитие партнерских отношений с соответствующими западными организациями ПВО. До сих пор наиболее важным было сотрудничество с Национальным университетом обороны Румынии. Эти отношения были критически важными для успеха работы ПСОСО.

Последний фактор относится к важности множества международных и национальных программ, которые дают свой вклад в профессиональное военное образование. Для страны как Молдова у которой относительно небольшие вооруженные силы, императивной необходимостью является использование возможностей для профессионального военного образования и квалификации, которые предлагают другие страны НАТО и страны-партнеры. В дополнение к образовательным возможностям, которые предоставляет молдавским офицерам Румыния, очень важной остается программа Международного военного образования и квалификации (МВОК), предлагаемая Соединенными Штатами. Отправление слушателей в иностранные военные институции погружает их в языковую среду и оперативные подходы, которые не могут быть воспроизведены в принимающей стране. Для государств, которые используют эти возможности важно обеспечить вакансии для тех офицеров, которые вернутся в МВА или в учебные базы, чтобы поделиться приобретенными знаниями с возможно наиболее широкой аудиторией. Предлагаемые места по МВАК надо сбалансировано распределить между действующими частями и учебными заведениями. Молдавские офицеры так же могут воспользо- 
ваться и такими программами НАТО как Колледж обороны НАТО, Школа НАТО и Курс высших командных исследований в Балтийском колледже обороны. Все эти программы являются важным дополнением к молдавским курсам ПВО.

Два основных источника поддержки для составления графика, привлечения специалистов и финансирования ПСОСО были КПРМ при Центре им. Джорджа К. Маршалла и отдел образовательных программ в сфере обороны Международного секретариата НАТО. С точки зрения США было важно координировать деятельность ПСОСО с рабочей группой принимающей стороны в отделе по сотрудничеству в сфере обороны (ОССО) и военным атташе. ОССО оказал неоценимую помощь во всей работе ПСОСО. Один из важных аспектов этого сотрудничества была связь инициативы ПСОСО с Планом кампании для данной страны Европейского командования вооруженных сил США. В результате были запланированы и профинансированы дополнительные мероприятия, кроме тех, которые обеспечивал КПРМ. Так же обязательно, чтобы все заинтересованные стороны - включая Европейское командование, Агентство по сотрудничеству в обороне и безопасности и соответствующие департаменты министерства обороны - были информированы и принимали участие в поддержке ПСОСО. Синхронизация всех этих субъектов способствует выполнению программы.

\section{Продолжение трансформации}

MBA продолжает осуществлять изменения в своем основном курсе, готовится к анализу и второй итерации учебного плана курса для старших офицеров. Для продолжения уже достигнутого прогресса, важно чтобы разные организации, оказывающие поддержку ПСОСО, и дальше продолжили предоставление своей помощи. Как показано в перспективном плане, инициативы ПСОСО как правило рассчитаны на три года, по истечении которых предполагается, что принимающие страны будут уже самодостаточными. Хотя эти программы становятся все более зрелыми, самодостаточность не является ни желательной, ни реалистической целью. Многонациональные операции и межправительственные действия являются интегральной частью успешной военной и оборонной деятельности, и поэтому они должны оставаться важной частью функционирования институций ПВО. Партнеры ПСОСО и поддерживающие организации должны и дальше оказывать поддержку МВА и другим партнерам ПСОСО путем предоставления услуг экспертов для чтения лекций и ведения сессий по разработке учебных планов. Такие сессии усиливают значение программ ПВО для слушателей и руководства странпартнеров и являются неоценимым вкладом в образование военных офицеров и профессиональных кадров национальной безопасности. Не менее важно продолжить и работу по усовершенствованию квалификации преподавательского состава. Во всех институциях ПВО существует текучество кадров и поэтому для организаций, поддерживающих ПСОСО, необходимо продолжить проведение семинаров по методике преподавания. Прием на работу и удержание качественного преподавательского состава является вероятно центром тяжести для долгосроч- 
ного успеха этих программ и продолжение участия в программах, связанных с ПСОСО, поможет таким усилиям.

Работа ПСОСО была направлена на развитие интеллектуальной оперативной совместимости, и поэтому сосредоточена на то чему учить и как учить. Но по мере взросления этих программ, надо обратить внимание и на другие образовательные потребности. Большинство стран-реципиентов по программам ПСОСО не имеют адекватных библиотечных ресурсов для обеспечения полного спектра курсов ПВО западного типа. Другие образовательные ресурсы, такие как технические средства для занятий и определенные инфраструктурные потребности, могут не быть на достаточной высоте для поддержки соответствующей среды обучения. Такие ресурсы не входят в прерогативы ПСОСО, но для решения наиболее серьезных проблем должны быть разработаны некоторые альтернативные средства. В случае МВА, правительство Швейцарии оказало помощь библиотеке в расширении ассортимента книг и материалов, связанных с профессиональным обучением, военной историей и геополитикой. Главные финансирующие организации, в том числе Международный секретариат НАТО и КПРМ, должны найти способы идентифицировать потребности и находить подходящих доноров.

\section{Заключение}

ПСОСО-Молдова была сфокусирована на развитии институционального потенциала Молдавской военной академии, для обеспечения высококачественного военного образования молодому поколению офицеров, которое даст свой вклад в строительство устойчивого и безопасного общества. Включение в учебные планы предметов, характерных для западного профессионального военного образования будет способствовать профессионализации офицерского корпуса молдавских вооруженных сил. Реформа молдавской системы военного образования, улучшение программ и методологии обучения, будет способствовать полной трансформации вооруженных сил. Такая трансформация приведет к упорядочению процесса принятия решений будущими военными лидерами, к большей степени участия и совместных способностей с силами НАТО и ЕС, и к улучшению отношений между Республикой Молдова, членами НАТО и странами-партнерами. В более широком смысле, эта работа поддерживает инициативу НАТО о проведении Реформ в Образовании и Квалификации и деятельность фонда «Варшавская инициатива» США в деле укрепления оборонных институтов и профессионального военного образования. Инициатива ПСОСО является примером эффективного в ценовом отношении применения ограниченных ресурсов и аккумулирования вкладов множества государств в оказании помощи МВА для достижения ее образовательных целей. Значение продолжения содействия этим усилиям не может быть переоценено. Продолжение поддержки МВА приведет к устойчивым долгосрочным результатам, к закладыванию профессиональных основ вооруженных сил Республики Молдова. 
OCEHЬ 2012

\section{Литература}

Dempsey, Martin. Chairman's Corner: Strategic Direction to the Joint Force., 2012.

Gates, Robert M.. "Helping Others Defend Themselves: The Future of U.S. Security Assistance." Foreign Affairs (2010).

Summit Declaration on Defense Capabilities: Toward NATO Forces 2020. NATO Press Release, 2012.

Sustaining U.S. Global Leadership: Priorities for 21st Century Defense. Washington, D.C.: U.S. Department of Defense, 2012. 